\title{
Vigilância da Qualidade da Água para Consumo Humano: avaliando o grau de implementação das ações
}

\author{
Surveillance of drinking-water quality: \\ assessing the degree of implementation of actions
}

Blanca Lisseth Barragan Guzman ${ }^{1}$

Gerardo Nava Tovar ${ }^{2}$

Paula Dias Bevilacqua ${ }^{1}$

${ }^{1}$ Programa de PósGraduação em Medicina Veterinária, Departamento de Veterinária, Centro de Ciências Biológicas e da Saúde, Universidade Federal de Viçosa. Av. Peter Henry Rolfs s/n, Cidade Universitária. 36.570-900 Viçosa MG Brasil.blancalissethguz@ hotmail.com

${ }^{2}$ Grupo de Calidad del Agua, Subdirección

Laboratorio Nacional de Referencia, Dirección de Redes en Salud Pública, Instituto Nacional de Salud, Bogotá, Colombia.

\begin{abstract}
This study aims to evaluate the Drinking-Water Quality Surveillance Programme (DWQS) implemented in Colombia. The study was conducted using methodology for assessing the implementation, integrating a normative assessment and evaluation research. For this assessment, Delphi methodology was developed that allowed the definition of an evaluation matrix, composed of 14 attributes and 62 criteria, as well as the building of a score system and parameters that permitted the evaluation of each of the defined criteria. Data collection involved conducting semi-structured interviews with institutional actors from 39 territorial units. The system evaluation showed that the DWQS in Colombia is partially implemented, with different stages of implementation in territorial units. The system showed a strengthening in actions related to data production on the aspect for improving water quality and DWQS actions from the standpoint of health promotion. However, some conceptual limitations were identified in terms of legislation thereby affecting the fulfilment of the universality of DWQS actions.
\end{abstract}

Key words Surveillance, Water quality, Delphi Methodology, Evaluation, Health planning
Resumo O presente estudo teve como objetivo avaliar a implementação do Sistema de Vigilância da Qualidade da Água para Consumo Humano (VQACH), na Colômbia. O estudo foi realizado mediante a metodologia de avaliação da implementação, integrando avaliação normativa e pesquisa de avaliação. Para a avaliação foi desenvolvida metodologia Delphi, permitindo definir uma matriz avaliativa, composta por 14 atributos e 62 critérios, e a construção de um sistema de escores e parâmetros, que possibilitou a avaliação de cada um dos critérios definidos. A coleta de dados envolveu a realização de entrevistas semiestruturadas com atores institucionais de 39 unidades territoriais. A avaliação mostrou que o sistema de $V Q A C H$ está parcialmente implementado, com diferentes estados de implementação nas unidades territoriais. O sistema mostra um fortalecimento nas ações relacionadas com produção de dados sobre as condições da qualidade da água, com ausência de ações que permitam o aproveitamento desses dados para o melhoramento da qualidade de água, e de ações de VQACH na perspectiva de promoção da saúde. Foram identificadas algumas limitações conceituais nas legislações, o que afeta o cumprimento da universalidade das ações de VQACH.

Palavras-chave Vigilância, Qualidade da água, Metodologia Delphi, Avaliação, Planejamento em Saúde 


\section{Introdução}

A avaliação em Saúde é tema emergente na América Latina, devido a crescentes demandas de maior acesso e qualidade dos serviços de Saúde, sendo essencial contar com programas e estratégias que respondam de maneira eficiente às diferentes necessidades das populações. Iniciativas de avaliação em Saúde, desenvolvidas em distintos contextos de programas e intervenções na região, têm produzido diferentes saberes, aprendizagens e reflexões sobre práticas de Saúde, contribuindo para seu aperfeiçoamento. Entretanto, apesar de promissor, o campo da avaliação em saúde apresenta diferentes desafios, principalmente no que diz respeito à necessidade de metodologias apropriadas, que permitam identificar e valorar os processos e resultados das intervenções nos diversos cenários existentes. Além disso, deve permitir abordagens que integrem dimensões políticas, sociais, econômicas, de qualidade de vida e de equidade, que se inter-relacionem e impactem as intervenções em saúde ${ }^{1,2}$.

Na Colômbia, a Saúde Ambiental, legalmente instituída como política integral de Saúde em 2008, vem se consolidando como estratégia fundamental para melhoramento da Saúde no país, sendo, recentemente, definida como um dos principais objetivos a serem abordados no "Plano Decenal de Saúde Pública 2012-2021”3,4. Entre as ações desenvolvidas no país, tem-se a Vigilância da Qualidade da Água para Consumo Humano VQACH, que objetiva diminuir os riscos à Saúde causados pelo consumo de água e melhoramento progressivo da qualidade da mesma. Apesar dos programas de VQACH terem amplo reconhecimento no âmbito internacional, poucos são os países na América Latina que contam com ações de VQCH estruturadas e instituídas legalmente, entre eles a Colômbia e o Brasil ${ }^{5}$.

Ações de VQACH na Colômbia existem formalizadas desde 1979, com a publicação do Código Nacional Sanitário (Lei n. ${ }^{\circ}$ 9/1979) que estabelece a regulação do abastecimento de água, definindo o Ministério da Saúde como órgão competente para a formulação das diretrizes, definições e instrumentos afetos ao abastecimento de água potável. Mais recentemente, as ações de VQACH passam a ser organizadas de forma mais sistemática com a publicação do Decreto n. ${ }^{\circ} 1.575 / 2007$, que cria o "Sistema de Proteção e Controle da Qualidade da Água para Consumo Humano". Segundo o Decreto, a VQACH deve ser realizada pelas autoridades de Saúde de forma periódica, para comprovar e avaliar o risco que representa à Saúde Pública a água distribuída, garantindo à população acesso à água em qualidade compatível com o padrão de potabilidade estabelecido no Decreto n. ${ }^{\circ}$ 2.115/20076.

O Decreto $\mathrm{n}^{\circ} 1.575 / 2007$ trouxe importantes inovações como: consolidação das ações de proteção da água integrando diferentes setores; estabelecimento das responsabilidades para as ações de controle e vigilância e suas interfaces, permitindo uma gestão mais dinâmica e competente; constituição do Programa Interlaboratorial de Controle da Qualidade da Água Potável (PICCAP) e do Sistema de Informação para a Vigilância da Qualidade da Água Potável (SIVICAP), para apoiar os territórios e realizar o acompanhamento das ações e adoção da perspectiva holística na avaliação da qualidade da água, com o emprego de ferramentas de avaliação de risco aplicadas a todo o processo de produção de água (do manancial ao consumo) ${ }^{6}$.

O novo marco legal define que as ações de VQACH competem ao Ministério da Saúde e Proteção Social (MSPS) e ao Ministério do Ambiente, Moradia e Desenvolvimento Territorial (MAMDT), que elaboram e desenham os modelos conceituais, técnicos e operativos necessários para o desenvolvimento das ações de vigilância. No nível central, as ações são lideradas pelo MSPS, em colaboração com o Instituto Nacional da Saúde (INS). No contexto operativo, as ações de VQACH seguem um padrão de descentralização definido pelas Lei 60/1993 e Lei 10/1990, com atribuições específicas nas três esferas do governo, sendo o município o principal executor das ações. Assim, as práticas de vigilância obedecem à regulação exercida pelo nível central, guardando, porém, a autonomia dos municípios, permitindo a complementação e/ou adequação das ações, considerando as características e necessidades locais. $\mathrm{O}$ atual Sistema também contempla a regulação da prestação dos serviços de abastecimento de água, Lei n. ${ }^{\circ}$ 142/1994, mediante a Superintendência de Serviços Públicos Domiciliários (SSPD), que supervisiona o cumprimento das disposições pelos responsáveis por sistemas de abastecimento e a Comissão de Regulação da Água Potável e Saneamento Básico (CRA), que regula os monopólios dos prestadores de serviços, garantindo acesso ao serviço em quantidade razoável e justa. Configuram-se, assim, novos cenários de prática sanitária nesse país.

Tem-se, então, um intervalo de sete anos desde a criação do Sistema de Proteção e Controle da Qualidade da Água para Consumo Humano sem, contudo, terem sido produzidos trabalhos visan- 
do sua avaliação. A avaliação em Saúde é importante procedimento que pode fornecer evidências para o aprimoramento e fortalecimento das ações de VQACH nos contextos Latino-Americanos, dando resposta aos crescentes desafios da Saúde Ambiental existentes nessa região. Assim, esse trabalho objetivou avaliar a implementação do Sistema de VQACH nos diferentes contextos onde se insere, procurando identificar problemas e desafios, de forma a apoiar e aprimorar suas ações, promovendo seu fortalecimento. Além de contribuir com avanços para o sistema colombiano, acreditamos que o trabalho também cumpre com o objetivo de incentivar iniciativas de aprimoramento de ações no campo da VQA$\mathrm{CH}$ em outros países, oportunizando a troca de experiências.

\section{Métodos}

A implementação do Sistema de VQACH na Colômbia foi analisada através de pesquisa avaliativa tipo análise de implementação $1 \mathrm{~b}$, envolvendo a avaliação normativa, para estimar o grau de implementação do Sistema, e pesquisa avaliativa para analisar os determinantes contextuais que influenciam o grau de implementação do Sistema de VQACH na Colômbia ${ }^{7}$. A abordagem metodológica para a análise da implementação foi o estudo de caso ${ }^{8}$. Além disso, procurou-se estudar de forma qualitativa as variáveis avaliativas mediante análise de conteúdo ${ }^{9}$. A abordagem proposta visou aproveitar recursos qualitativos e quantitativos, permitindo diálogo desejável entre a dimensão da objetividade e da subjetividade, que comumente se integram para a conformação das intervenções na Saúde.

\section{Seleção de casos}

Na Colômbia, as unidades territoriais são classificadas segundo o porte populacional, assim, os estados são categorizados em: 'especial' (>2.000.000 hab.), '1' (700.001-2.0000.000 hab.), '2' (391.001-700.000 hab.), '3' (100.001-390.000 hab.) e '4' (< 100.000 hab.) e os municípios em: 'especial' (> 500.001 hab.), '1' (100.001-500.000 hab.), ' 2 ' (50.001-100.000 hab.), '3' (30.00150.000 hab.), '4' (20.001-30.000 hab.), '5' (10.00020.001 hab.) e ' 6 ' $(<10.000 \text { habitantes })^{10}$. As ações da VQACH devem ser desenvolvidas pelos estados e pelos municípios categorias 'especial', '1', '2' e ' 3 ', certificados como descentralizados; nos municípios categorias '4', '5' e '6', o respon- sável pelo desenvolvimento das ações é o estado. $\mathrm{Na}$ época do estudo, o país totalizava 32 estados e 1.102 municípios $^{11}$. Dentre os municípios, 61 (5,5\%) tinham atribuição de desenvolver ações de VQACH de forma independente; nos demais municípios (94,5\%), as ações eram desenvolvidas pelas autoridades estaduais de Saúde. Participaram da pesquisa 39 territórios (unidades de análises), sendo 27 (84,4\%) estados, incluindo o distrito capital (Bogotá), pelas características populacionais e socioeconômicas, e 12 (19,7\%) municípios dentre os que desenvolviam ações de forma independente.

\section{Modelo Lógico}

A construção do modelo lógico permitiu apreciar a arquitetura do Sistema de VQACH e selecionar os atributos e critérios para avaliação; sua elaboração se deu a partir da análise documental de portarias, documentos, relatórios e informes sobre a VQACH na Colômbia como: Decreto n. ${ }^{\circ}$ 1.575/2007, Resolução n. ${ }^{\circ}$ 2.115/2007, Resolução n. ${ }^{\circ}$ 811/2008, Resolução n. ${ }^{\circ} 82 / 2009$, Resolução n. ${ }^{\circ} 4.716 / 2010$ e outros documentos produzidos pelo INS e MSPS. Seguindo a lógica do Sistema de VQACH, foram identificados objetivos, atores vinculados, atividades, resultados intermediários e resultados finais (Figura 1). O modelo lógico foi apresentado e discutido no INS, para seu aperfeiçoamento e para aumentar a adesão dos atores no processo avaliativo.

\section{Atributos, critérios \\ e parâmetros de avaliação}

Para a avaliação da implementação do Sistema, foi elaborada matriz de julgamento, construída mediante seleção de atributos e critérios e definição dos parâmetros para avaliar o Sistema e os determinantes contextuais. No estudo, procuramos garantir a validade interna considerando: (i) a aproximação do modelo lógico com a realidade do Sistema de VQACH e (ii) a adequação entre o modelo teórico e o método de análise escolhido, observada na seleção dos atributos e critérios utilizados na avaliação ${ }^{12}$.

Para seleção dos atributos e critérios, foi utilizada a metodologia Delphi ${ }^{13}$, permitindo definir, a partir do consenso entre especialistas, a pertinência do uso dos atributos e critérios propostos pelos pesquisadores para a avaliação. A metodologia Delphi contou com grupo de sete especialistas, formado por professores e pesquisadores que trabalhavam com o tema de estudo 


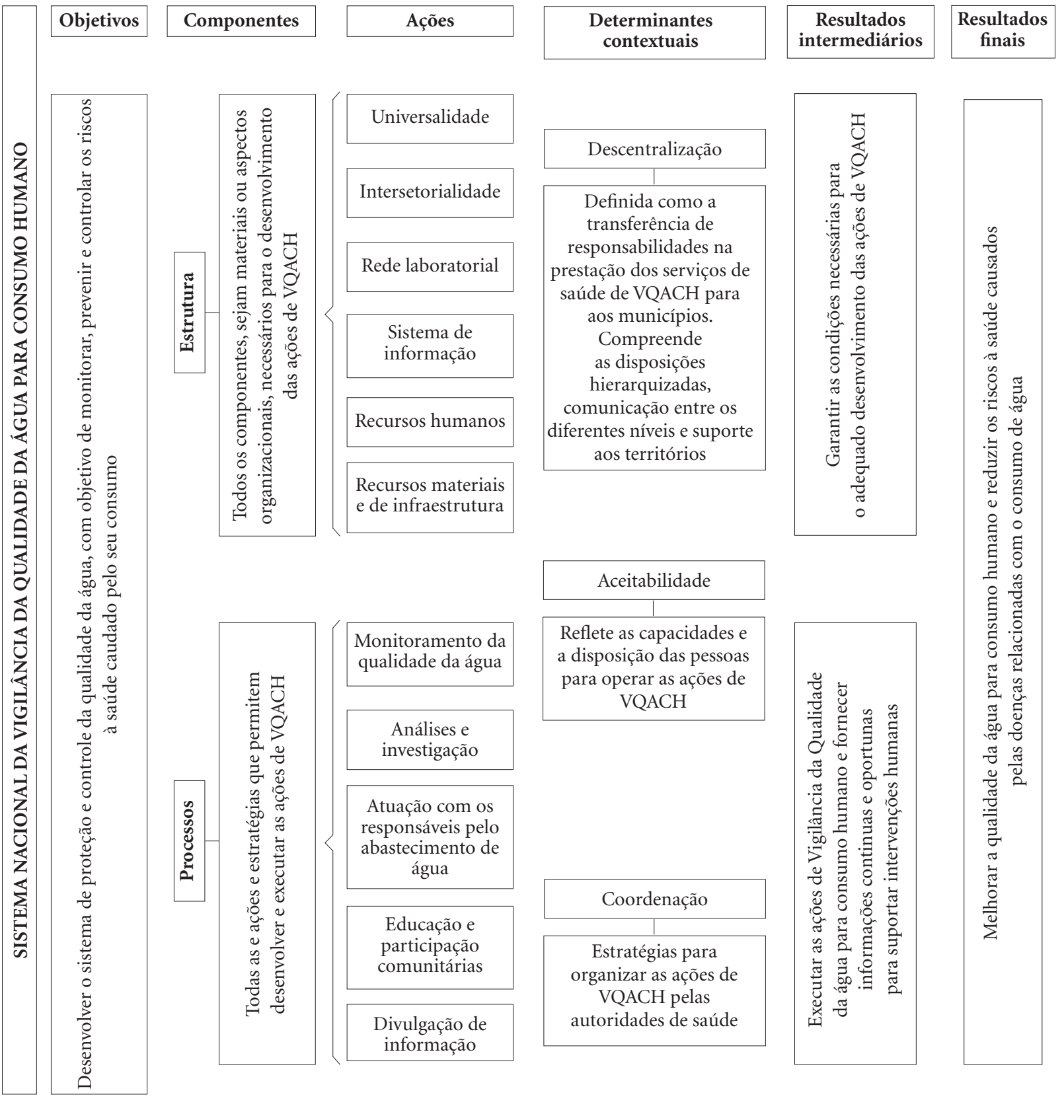

Figura 1. Modelo lógico do Sistema de Vigilância da Qualidade da Água para Consumo Humano, Colômbia.

e profissionais que atuavam na área da vigilância da qualidade da água no Brasil e na Colômbia.

A matriz avaliativa foi composta por 14 atributos e 62 critérios, sendo 11 atributos e 45 critérios relativos à avaliação do grau de implementação do Sistema de VQACH e três atributos e 17 critérios para análise dos determinantes contextuais (Quadros 1 e 2). Os atributos para avaliação do Sistema foram conformados por seis atributos do componente 'estrutura' (universalidade, intersetorialidade, sistemas de informação, rede laboratorial, recursos humanos, recursos materiais e infraestrutura) e cinco atributos de 'processo' (monitoramento da qualidade da água, atuação junto aos responsáveis pelas fontes de distribuição da água, análise e investigação, educação e participação comunitárias e disponibilização de informações). Foram considerados como atribu- 


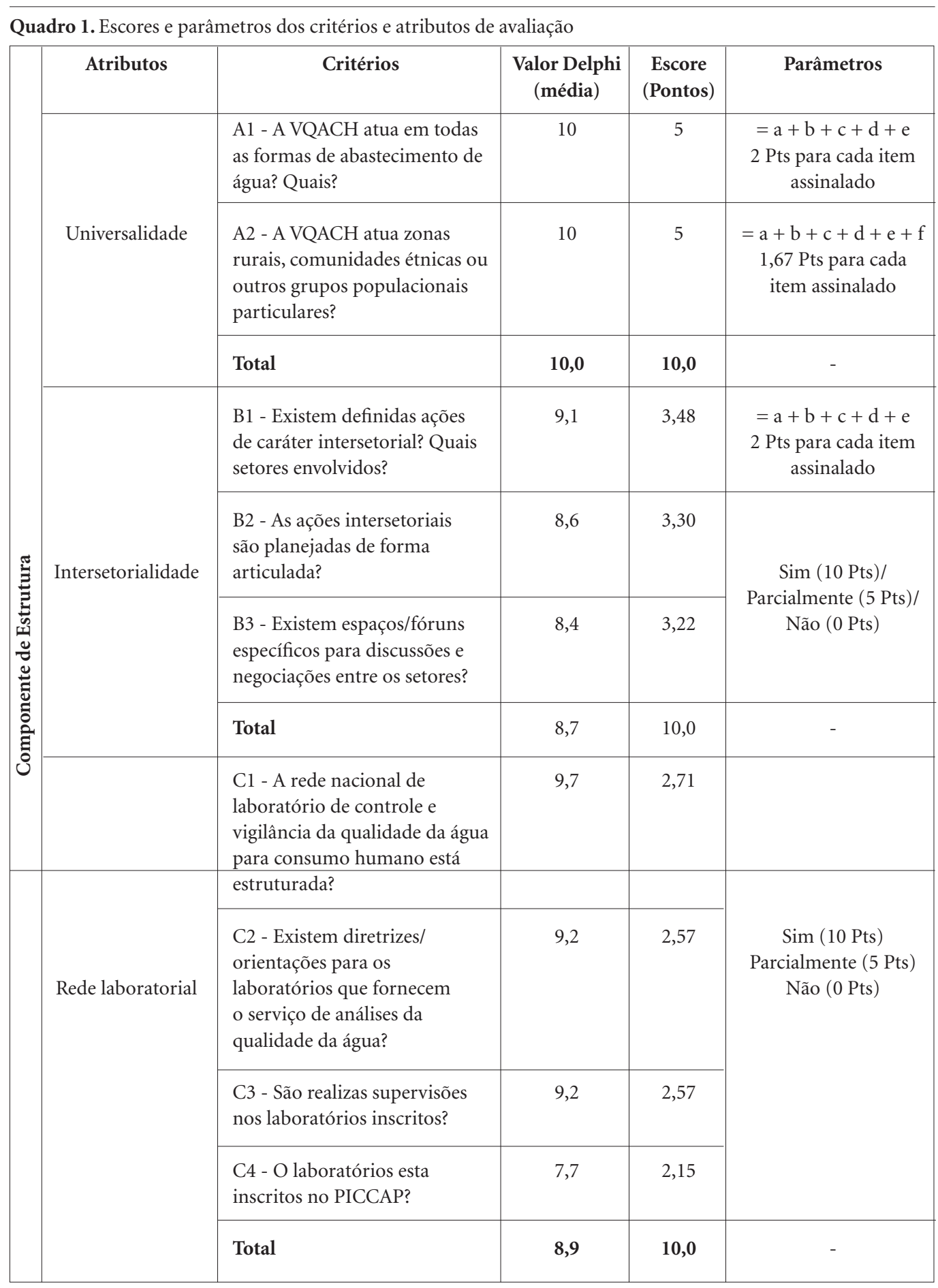

continua

tos contextuais 'descentralização', 'aceitabilidade' e 'coordenação', seguindo o modelo de desenvolvimento organizacional proposto por Denis e Champagne ${ }^{14}$.

Para avaliação do grau de implementação do Sistema, cada território recebeu uma nota final calculada a partir do somatório das pontuações obtidas em cada um dos 11 atributos definidos para essa etapa, as quais, por sua vez, foram obtidas a partir do somatório das pontuações de cada critério. Para a pontuação total em cada atributo, os critérios foram elaborados como perguntas, sendo as respostas pontuadas para objetivar e quantificar as categorias avaliadas, caracterizan- 
Quadro 1. continuação

\begin{tabular}{|c|c|c|c|c|c|}
\hline & Atributos & Critérios & $\begin{array}{l}\text { Valor Delphi } \\
\text { (média) }\end{array}$ & $\begin{array}{c}\text { Escore } \\
\text { (Pontos) }\end{array}$ & Parâmetros \\
\hline \multirow{14}{*}{ 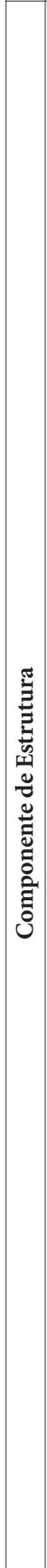 } & \multirow{7}{*}{$\begin{array}{l}\text { Sistemas de } \\
\text { informação }\end{array}$} & $\begin{array}{l}\text { D1 - Existem sistemas de } \\
\text { informação específicos para } \\
\text { VQACH? }\end{array}$ & 9,6 & 1,74 & \multirow{6}{*}{$\begin{array}{l}\text { Sim }(10 \text { Pts }) \\
\text { Parcialmente }(5 \text { Pts }) \\
\text { Não }(0 \text { Pts })\end{array}$} \\
\hline & & $\begin{array}{l}\text { D2 - O sistema de informação } \\
\text { é alimentado? }\end{array}$ & 9,6 & 1,74 & \\
\hline & & $\begin{array}{l}\text { D3 - Existe profissional } \\
\text { específico para alimentação do } \\
\text { sistema de informação? }\end{array}$ & 8,6 & 1,56 & \\
\hline & & $\begin{array}{l}\text { D4 - O profissional é } \\
\text { capacitado? }\end{array}$ & 9,0 & 1,63 & \\
\hline & & $\begin{array}{l}\text { D5 - São realizados } \\
\text { treinamentos/cursos sobre o } \\
\text { funcionamento do/s sistema/s } \\
\text { de informação/ões? }\end{array}$ & 9,0 & 1,63 & \\
\hline & & $\begin{array}{l}\text { D6 - Conhece o fluxo da } \\
\text { informação? }\end{array}$ & 9,5 & 1,72 & \\
\hline & & Total & 9,2 & 10,0 & - \\
\hline & \multirow{7}{*}{ Recursos humanos } & $\begin{array}{l}\text { E1 - Número de profissionais } \\
\text { que desenvolvem as ações de } \\
\text { VQACH por unidades (estados } \\
\text { e municípios)? }\end{array}$ & 9,4 & 1,80 & \multirow{5}{*}{ Conforme Quadro 2} \\
\hline & & $\begin{array}{l}\text { E2 - Qual é a formação do } \\
\text { coordenador das ações de } \\
\text { VQACH? }\end{array}$ & 8,0 & 1,53 & \\
\hline & & $\begin{array}{l}\text { E3 - O coordenador das } \\
\text { ações de VQACH atua } \\
\text { exclusivamente na área? }\end{array}$ & 8,0 & 1,53 & \\
\hline & & $\begin{array}{l}\mathrm{E} 4-\mathrm{O} \text { coordenador tem } \\
\text { experiência na área de } \\
\text { VQACH? }\end{array}$ & 8,7 & 1,12 & \\
\hline & & $\begin{array}{l}\text { E5 - Qual o tipo de vínculo } \\
\text { profissional com o serviço? }\end{array}$ & 8,7 & 1,26 & \\
\hline & & $\begin{array}{l}\text { E6 - Os profissionais recebem } \\
\text { algum tipo de capacitação/ } \\
\text { treinamentos? }\end{array}$ & 9,4 & 0,75 & $\begin{array}{l}\text { Sim (10 Pts) } \\
\text { Parcialmente (5 Pts) } \\
\text { Não (0 Pts) }\end{array}$ \\
\hline & & Total & 8,7 & 10,0 & - \\
\hline
\end{tabular}




\begin{tabular}{|c|c|c|c|c|c|}
\hline \multicolumn{6}{|c|}{ Quadro 1. continuação } \\
\hline & Atributos & Critérios & $\begin{array}{l}\text { Valor Delphi } \\
\text { (média) }\end{array}$ & $\begin{array}{c}\text { Escore } \\
\text { (Pontos) }\end{array}$ & Parâmetros \\
\hline \multirow{3}{*}{ 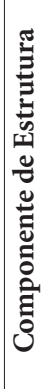 } & \multirow{3}{*}{ Recursos materiais } & $\begin{array}{l}\text { F1 - Existem recursos materiais } \\
\text { e de infraestrutura para o } \\
\text { desenvolvimento das ações de } \\
\text { VQACH? }\end{array}$ & 9,4 & 5,11 & \multirow{2}{*}{$\begin{array}{l}\text { Sim }(10 \text { Pts }) \\
\text { Parcialmente (5 Pts) } \\
\text { Não (0 Pts) }\end{array}$} \\
\hline & & $\begin{array}{l}\text { F2 - Existe orçamento para } \\
\text { aquisição de recursos materiais } \\
\text { e de infraestrutura? }\end{array}$ & 9,0 & 4,89 & \\
\hline & & Total & 9,2 & 10,0 & - \\
\hline \multirow{5}{*}{ 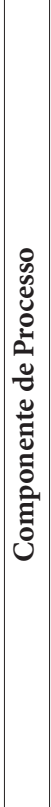 } & \multirow{5}{*}{$\begin{array}{l}\text { Atributos } \\
\text { Monitoramento da } \\
\text { qualidade da água }\end{array}$} & $\begin{array}{l}\text { G1 - Existe um plano próprio } \\
\text { de monitoramento da } \\
\text { VAQCH? }\end{array}$ & 9,0 & 2,48 & \multirow{4}{*}{$\begin{array}{l}\text { Sim (10 Pts) } \\
\text { Parcialmente (5 Pts) } \\
\text { Não (0 Pts) }\end{array}$} \\
\hline & & $\begin{array}{l}\text { G2 - Realiza as ações de } \\
\text { vigilância das características } \\
\text { química e microbiológica da } \\
\text { qualidade da água e consumo? }\end{array}$ & 9,7 & 2,67 & \\
\hline & & $\begin{array}{l}\text { G3 - São coletados os dados } \\
\text { necessários para calcular os } \\
\text { índice de risco e elaborar o } \\
\text { mapa de risco? }\end{array}$ & 8,4 & 2,31 & \\
\hline & & $\begin{array}{l}\text { G4 - É realizada a supervisão } \\
\text { do monitoramento dos } \\
\text { agrotóxicos pelas secretarias } \\
\text { sanitárias de acordo com a } \\
\text { portaria } 1843 / 1991 \text { ? }\end{array}$ & 9,2 & 2,53 & \\
\hline & & Total & 9,1 & 10,0 & - \\
\hline
\end{tabular}

continua

do, assim, os 'parâmetros dos critérios'. A maioria das perguntas admitia respostas do tipo 'sim', 'não' ou 'parcialmente', sendo atribuídos 10 pontos para resposta 'sim'; cinco para resposta 'parcialmente' e zero para resposta 'não' (Quadro 1). Alguns critérios (A1, A2, B1 e do E1 ao E5) não permitiram respostas pontuais, assim, para os critérios A1, A2 e B1, a pontuação máxima (10) foi dividida igualmente entre cada categoria (cinco para os critérios A1 e B1 e seis para A2).

Para o critério E1, foram utilizados dois parâmetros para a pontuação (parâmetro A e parâmetro $B$ ), sendo atribuídos cinco pontos a cada um. O parâmetro A foi definido considerandose um número mínimo de técnicos aceitáveis por território (estado ou município). Para cada estado, foi calculada a razão entre o número de técnicos que desenvolviam ações de VQACH e o número de municípios. Para os municípios, a definição do número aceitável de técnicos considerou recortes populacionais: um técnico para municípios com menos de 100.000 habitantes e, a partir de 100.001 habitantes, o número de técnicos era aumentado em dois para cada acréscimo de até 500.000 habitantes na população. Esses recortes foram baseados nos critérios utilizados para definição das frequências e número mínimo de amostras para o monitoramento da qualidade da agua ${ }^{15}$. Foram, então, calculadas as razões do número de técnico aceitável considerando os recortes populacionais. A pontuação final do parâmetro A foi definida conforme Quadro 2; o parâmetro $\mathrm{B}$ considerou a atuação dos técnicos na área de VQACH, sendo atribuídos pontos 


\begin{tabular}{|c|c|c|c|c|c|}
\hline \multicolumn{6}{|c|}{ Quadro 1. continuação } \\
\hline \multirow{14}{*}{ 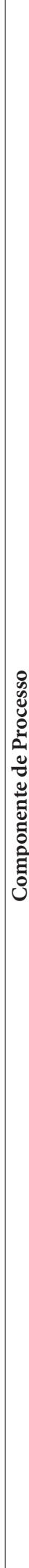 } & Atributos & Critérios & $\begin{array}{l}\text { Valor Delphi } \\
\text { (média) }\end{array}$ & $\begin{array}{c}\text { Escore } \\
\text { (Pontos) }\end{array}$ & Parâmetros \\
\hline & \multirow{8}{*}{$\begin{array}{l}\text { Análises e } \\
\text { investigação }\end{array}$} & $\begin{array}{l}\text { H1 - Existe análise integrada } \\
\text { entre o banco de dados da } \\
\text { VQACH com outros sistemas } \\
\text { de informação? }\end{array}$ & 8,7 & 1,33 & \multirow{7}{*}{$\begin{array}{l}\operatorname{Sim}(10 \text { Pts }) / \\
\text { Parcialmente }(5 \text { Pts }) / \\
\text { Não }(0 \text { Pts })\end{array}$} \\
\hline & & $\begin{array}{l}\mathrm{H} 2 \text { - É elaborado o mapa } \\
\text { de risco pelas autoridades } \\
\text { ambientais e sanitárias? }\end{array}$ & 8,7 & 1,33 & \\
\hline & & $\begin{array}{l}\text { H3 - São realizadas } \\
\text { investigações no caso dos } \\
\text { resultados não atingir os } \\
\text { parâmetros de qualidade } \\
\text { estabelecidos pela legislação? }\end{array}$ & 10,0 & 1,53 & \\
\hline & & $\begin{array}{l}\text { H4 - São realizadas } \\
\text { investigações de surtos } \\
\text { relacionados com a qualidade } \\
\text { da água para consumo? }\end{array}$ & 9,7 & 1,49 & \\
\hline & & $\begin{array}{l}\text { H5 - É realizado o diagnóstico } \\
\text { final da qualidade da água para } \\
\text { consumo em cada unidade } \\
\text { (estado/município)? }\end{array}$ & 9,5 & 1,46 & \\
\hline & & $\begin{array}{l}\text { H6 - São elaborados relatórios } \\
\text { sobre as análises realizadas? }\end{array}$ & 9,0 & 1,38 & \\
\hline & & $\begin{array}{l}\text { H7- A partir das análises locais } \\
\text { e nacionais é planejada a } \\
\text { tomada de decisões? }\end{array}$ & 9,6 & 1,47 & \\
\hline & & Total & 9,3 & 10,0 & - \\
\hline & \multirow{5}{*}{$\begin{array}{l}\text { Atuação junto } \\
\text { aos responsáveis } \\
\text { pelas fontes de } \\
\text { distribuição da } \\
\text { água }\end{array}$} & $\begin{array}{l}\text { I1 -São realizadas visitas para } \\
\text { fiscalizar o autocontrole dos } \\
\text { sistemas de abastecimento de } \\
\text { água? }\end{array}$ & 9,7 & 2,59 & \multirow{4}{*}{$\begin{array}{l}\operatorname{Sim}(10 \text { Pts }) / \\
\text { Parcialmente }(5 \text { Pts }) / \\
\text { Não }(0 \text { Pts })\end{array}$} \\
\hline & & $\begin{array}{l}\text { I2- São realizadas visitas de } \\
\text { inspeção sanitária dos sistemas } \\
\text { de abastecimento de água? }\end{array}$ & 9,4 & 2,51 & \\
\hline & & $\begin{array}{l}\text { I3- As ações de intervenção da } \\
\text { VQACH são discutidas com o } \\
\text { prestador do serviço? }\end{array}$ & 9,1 & 2,43 & \\
\hline & & $\begin{array}{l}\text { I4 - As intervenções } \\
\text { são realizadas de forma } \\
\text { coordenada entre a VQACH e } \\
\text { o prestador de serviço? }\end{array}$ & 9,3 & 2,48 & \\
\hline & & Total & 9,4 & 10,0 & - \\
\hline
\end{tabular}




\begin{tabular}{|c|c|c|c|c|c|}
\hline \multicolumn{6}{|c|}{ Quadro 1. continuação } \\
\hline \multirow{10}{*}{ 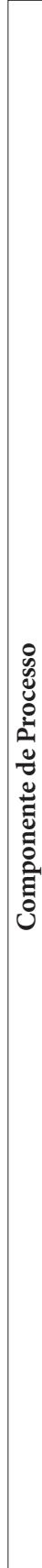 } & Atributos & Critérios & $\begin{array}{l}\text { Valor Delphi } \\
\text { (média) }\end{array}$ & $\begin{array}{c}\text { Escore } \\
\text { (Pontos) }\end{array}$ & Parâmetros \\
\hline & \multirow{5}{*}{$\begin{array}{l}\text { Atributos } \\
\text { Educação e } \\
\text { participação } \\
\text { Comunitárias }\end{array}$} & $\begin{array}{l}\text { J1 - São realizadas atividades } \\
\text { de educação em saúde } \\
\text { envolvendo o tema qualidade } \\
\text { da água e outros afins? }\end{array}$ & 9,0 & 2,73 & \multirow{4}{*}{$\begin{array}{l}\operatorname{Sim}(10 \text { Pts }) / \\
\text { Parcialmente }(5 \text { Pts }) / \\
\text { Não }(0 \text { Pts })\end{array}$} \\
\hline & & $\begin{array}{l}\text { J2 - Existem programas/ações/ } \\
\text { atividades para incentivar a } \\
\text { participação da comunidade } \\
\text { para o uso adequado / } \\
\text { conservação/manipulação } \\
\text { da qualidade da água para } \\
\text { consumo? }\end{array}$ & 8,7 & 2,64 & \\
\hline & & $\begin{array}{l}\text { J3 - As comunidades } \\
\text { participam da execução das } \\
\text { ações de VQACH? }\end{array}$ & 7,1 & 2,15 & \\
\hline & & $\begin{array}{l}\text { J4 - São fornecidas } \\
\text { informações sobre as } \\
\text { responsabilidades dos usuários } \\
\text { na preservação da qualidade da } \\
\text { água para consumo humano? }\end{array}$ & 8,2 & 2,48 & \\
\hline & & Total & 8,2 & 10,0 & - \\
\hline & \multirow{4}{*}{$\begin{array}{l}\text { Disponibilização } \\
\text { de informações }\end{array}$} & $\begin{array}{l}\text { K1 - Todos os setores } \\
\text { relacionados ao abastecimento } \\
\text { de água para consumo } \\
\text { humano têm acesso às } \\
\text { informações sobre qualidade } \\
\text { da água? }\end{array}$ & 9,8 & 3,29 & \multirow{3}{*}{$\begin{array}{l}\operatorname{Sim}(10 \text { Pts }) / \\
\text { Parcialmente }(5 \mathrm{Pts}) / \\
\text { Não }(0 \text { Pts })\end{array}$} \\
\hline & & $\begin{array}{l}\text { K2 - São fornecidas } \\
\text { informações para a } \\
\text { comunidade sobre a qualidade } \\
\text { da água distribuída? }\end{array}$ & 10,0 & 3,36 & \\
\hline & & $\begin{array}{l}\text { K3 - Os consumidores são } \\
\text { informados sobre situações de } \\
\text { risco identificadas? }\end{array}$ & 10,0 & 3,36 & \\
\hline & & Total & 9,9 & 10,0 & - \\
\hline
\end{tabular}

continua

conforme Quadro 2. A pontuação final do critério foi a soma dos pontos dos parâmetros A e B.

Para os critérios E2, E3 e E4, foram consideradas as informações referentes apenas aos coordenadores das ações de VQACH. A pontuação do critério $\mathrm{E} 4$ considerou o tempo de atuação na área da VQACH, sendo a referência igual a quatro anos baseada na frequência com que ocorrem as mudanças na administração pública na , que é a cada quatro anos (Quadro 2). O critério E5 incluiu informações dos coordenadores e dos técnicos e foi pontuado considerando a relação de trabalho do profissional com o serviço, definida como desejável a vinculação formal do trabalhador com a instituição/órgão de saúde. Foram encontrados três tipos de vinculação: 'carreira 


\begin{tabular}{|c|c|c|c|c|c|}
\hline \multicolumn{6}{|c|}{ Quadro 1. continuação } \\
\hline & Atributos & Critérios & $\begin{array}{l}\text { Valor Delphi } \\
\text { (média) }\end{array}$ & $\begin{array}{c}\text { Escore } \\
\text { (Pontos) }\end{array}$ & Parâmetros \\
\hline \multirow{7}{*}{ 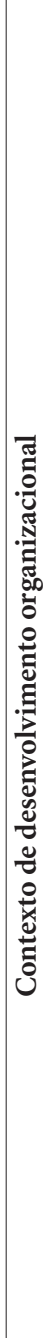 } & \multirow{7}{*}{ Descentralização } & $\begin{array}{l}\text { L1 - São definidas atribuições } \\
\text { gerenciais e administrativas } \\
\text { específicas de cada nível? }\end{array}$ & 8,9 & 1,48 & \multirow{7}{*}{$\begin{array}{l}\operatorname{Sim}(10 \text { Pts }) / \\
\text { Parcialmente }(5 \text { Pts }) / \\
\text { Não }(0 \text { Pts })\end{array}$} \\
\hline & & $\begin{array}{l}\text { L2 - Existe participação dos } \\
\text { três níveis (nacional/estadual/ } \\
\text { municipal) na definição de } \\
\text { estratégias descentralizadas? }\end{array}$ & 7,6 & 1,26 & \\
\hline & & $\begin{array}{l}\text { L3 - Existe participação dos } \\
\text { três níveis (nacional/estadual/ } \\
\text { municipal) no planejamento } \\
\text { das ações de VQACH? }\end{array}$ & 8,6 & 1,43 & \\
\hline & & $\begin{array}{l}\text { L4 - Existe integração e } \\
\text { articulação dos três níveis para } \\
\text { o desenvolvimento das ações } \\
\text { de VQACH? }\end{array}$ & 9,2 & 1,53 & \\
\hline & & $\begin{array}{l}\text { L5 - O nível nacional } \\
\text { desenvolve as ações } \\
\text { preconizadas? }\end{array}$ & 8,1 & 1,35 & \\
\hline & & $\begin{array}{l}\text { L6 - Existe suporte ou apoio } \\
\text { do nível nacional para o } \\
\text { desenvolvimento das ações de } \\
\text { VQACH no nível estadual e/ } \\
\text { ou municipal (e/ou suporte } \\
\text { do nível estadual para o nível } \\
\text { municipal)? }\end{array}$ & 8,8 & 1,46 & \\
\hline & & $\begin{array}{l}\text { L7 - Existem legislações que } \\
\text { garantam o orçamento para } \\
\text { aquisição de recursos materiais } \\
\text { e de infraestrutura? }\end{array}$ & 8,9 & 1,48 & \\
\hline
\end{tabular}

administrativa', 'profissional temporário' e 'contrato de prestação de serviços', sendo as duas primeiras caracterizadas como relação formal com a instituição e a última, trabalho temporário sem vínculo formal. A pontuação do critério considerou o cálculo do porcentual de profissionais com vínculo formal (Quadro 2).

Obtida a nota em cada critério, numa escala de 1 a 10, os valores foram recalculados tendo como referência o valor do 'escore do critério'. Para cálculo desse escore, inicialmente, para cada critério em um atributo, foi calculada a média das notas emitidas pelos avaliadores na meto- dologia Delphi. Considerando o somatório das médias em cada atributo, foi recalculado o valor para cada critério para um total máximo por atributo igual a 10. Obtida a pontuação final de cada atributo, esse valor foi transformado em um escore calculado segundo o mesmo procedimento descrito para a definição do 'escore do critério', sendo que, nesse caso, o valor máximo definido para o escore foi igual a 100.

A avaliação final do grau de implementação de cada território utilizou as seguintes categorias: implementado (75,1 a 100,0); parcialmente implementado $(50,1$ a 75,0$)$; incipiente $(25,1$ a 50,0$)$ e 


\begin{tabular}{|c|c|c|c|c|c|}
\hline \multicolumn{6}{|c|}{ Quadro 1. continuação } \\
\hline & Atributos & Critérios & $\begin{array}{l}\text { Valor Delphi } \\
\text { (média) }\end{array}$ & $\begin{array}{c}\text { Escore } \\
\text { (Pontos) }\end{array}$ & Parâmetros \\
\hline \multirow{10}{*}{ 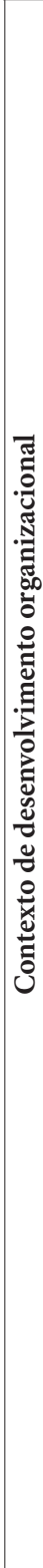 } & \multirow{8}{*}{ Aceitabilidade } & $\begin{array}{l}\text { M1 - Existe }(m) \text { dificuldade(s) } \\
\text { na compreensão de alguma } \\
\text { estratégia da VQACH? }\end{array}$ & 9,3 & 1,36 & \multirow{8}{*}{$\begin{array}{l}\text { Sim }(0 \text { Pts }) \\
\text { Parcialmente }(5 \text { Pts }) \\
\text { Não (10 Pts) }\end{array}$} \\
\hline & & $\begin{array}{l}\text { M2 - Os responsáveis pelo } \\
\text { desenvolvimento das ações de } \\
\text { VQACH têm conhecimento } \\
\text { das disposições da Portaria } \\
\text { 1575/2007 e suas diretrizes? }\end{array}$ & 10,0 & 1,46 & \\
\hline & & $\begin{array}{l}\text { M3 - os instrumentos de } \\
\text { análises de risco são utilizadas? }\end{array}$ & 8,1 & 1,18 & \\
\hline & & $\begin{array}{l}\text { M4 - Existem dificuldades na } \\
\text { compreensão os instrumentos } \\
\text { de análises de risco? }\end{array}$ & 7,9 & 1,15 & \\
\hline & & $\begin{array}{l}\text { M5 - Existem dificuldades } \\
\text { na aplicação/utilização das } \\
\text { instrumento de avaliação de } \\
\text { risco? }\end{array}$ & 7,9 & 1,15 & \\
\hline & & $\begin{array}{l}\text { M6 - Existem dificuldades no } \\
\text { preenchimento do formulário } \\
\text { de autocontrole? }\end{array}$ & 7,9 & 1,15 & \\
\hline & & $\begin{array}{l}\text { M7 - Existem dificuldades no } \\
\text { preenchimento do formulário } \\
\text { de inspeção sanitária? }\end{array}$ & 8,1 & 1,18 & \\
\hline & & $\begin{array}{l}\text { M8 -Existem dificuldades no } \\
\text { monitoramento da qualidade } \\
\text { da água? }\end{array}$ & 9,3 & 1,36 & \\
\hline & \multirow{2}{*}{ Coordenação } & $\begin{array}{l}\text { N1- Existe supervisão no } \\
\text { desenvolvimento dos planos } \\
\text { de ação? }\end{array}$ & 9,2 & 4,87 & \multirow{2}{*}{$\begin{array}{l}\operatorname{Sim}(10 \text { Pts }) / \\
\text { Parcialmente }(5 \text { Pts }) / \\
\text { Não (0 Pts) }\end{array}$} \\
\hline & & $\begin{array}{l}\text { N2 - Existe avaliação da } \\
\text { implementação dos planos de } \\
\text { ação? }\end{array}$ & 9,7 & 5,13 & \\
\hline
\end{tabular}

não implementado (menor ou igual a 25,0), conforme os níveis adotados por Souza et al. ${ }^{16}$.

Ainda como parte do trabalho, realizou-se análise qualitativa dos conteúdos das questões abertas do instrumento de coleta de dados. Foi utilizada a metodologia de Análise de Conteúdo proposta por Bardin'. Os resultados foram discutidos de forma simultânea aos resultados da avaliação da implementação.
As informações necessárias para a definição do grau de implementação do Sistema da VQA$\mathrm{CH}$ e para análise dos determinantes contextuais em cada unidade de análise foram obtidas mediante aplicação de questionário semiestruturado, elaborado a partir dos atributos e critérios selecionados e validado pelos pesquisadores e profissionais da área com relação à clareza e pertinência das questões. O questionário foi aplicado 
Quadro 2. Parâmetros de avaliação para o atributo recursos humanos, Colômbia.

\begin{tabular}{|c|c|}
\hline \multicolumn{2}{|c|}{ Parâmetros de avaliação para o atributo de Recursos Humanos } \\
\hline Critério & Parâmetro (pontos) \\
\hline $\begin{array}{l}\text { E1 - Número de profissionais que } \\
\text { desenvolvem as ações de VQACH por } \\
\text { unidades (estados e municípios) }\end{array}$ & $\begin{array}{l}\text { Parâmetro A: } \\
\geq 1=5 \text { pontos } \\
\leq 0,51 \text { e }<1=4 \text { pontos } \\
\leq 0,34 \text { e }<0,51=3 \text { pontos } \\
\leq 0,25 \text { e }<0,34=2 \text { pontos } \\
<0,25=1 \text { ponto } \\
\text { Parâmetro B: } \\
\text { Atuação exclusiva = } 5 \text { pontos } \\
\text { Atuação na VQACH e em mais uma área }=4 \text { pontos } \\
\text { Atuação na VQACH e em mais duas áreas }=3 \text { pontos } \\
\text { Atuação na VQACH e em mais três áreas }=2 \text { pontos } \\
\text { Atuação na VQACH e em mais quatro áreas = } 1 \text { ponto } \\
\text { Atuação na VQACH e em mais cinco ou mais áreas }=0 \text { ponto }\end{array}$ \\
\hline $\begin{array}{l}\text { E2 - Qual é a formação do } \\
\text { coordenador das ações de VQACH? } \\
\text { Existe capacitação específica? }\end{array}$ & $\begin{array}{l}\text { Pós-Graduação }=10 \text { pontos } \\
\text { Especialização }=8 \text { pontos } \\
\text { Graduação }=6 \text { pontos } \\
\text { Técnico }=4 \text { pontos } \\
\text { Nível médio ou outro }=0 \text { ponto }\end{array}$ \\
\hline $\begin{array}{l}\text { E3 - O coordenador das ações de } \\
\text { VQACH atua exclusivamente na área? }\end{array}$ & $\begin{array}{l}\text { Atuação exclusiva }=10 \text { pontos } \\
\text { Atuação na VQACH e em mais uma área }=8 \text { pontos } \\
\text { Atuação na VQACH e em mais duas áreas }=6 \text { pontos } \\
\text { Atuação na VQACH e em mais três áreas }=4 \text { pontos } \\
\text { Atuação na VQACH e em mais quatro áreas }=2 \text { pontos } \\
\text { Atuação na VQACH e em mais cinco ou mais áreas }=0 \text { ponto }\end{array}$ \\
\hline $\begin{array}{l}\mathrm{E} 4 \text { - O coordenador tem experiência } \\
\text { na área de VQACH? }\end{array}$ & $\begin{array}{l}\geq 4 \text { anos }=10 \text { pontos } \\
2 \text { a } 4 \text { anos }=5 \text { pontos } \\
\leq 2 \text { anos }=0 \text { ponto }\end{array}$ \\
\hline $\begin{array}{l}\text { E5 - Qual o tipo de vínculo } \\
\text { profissional com o serviço? }\end{array}$ & $\begin{array}{l}\text { Porcentual de profissionais com vínculo formal: igual a zero } \\
\text { quando não existiam profissionais com vínculo formal ou todos os } \\
\text { profissionais tinham vínculo tipo 'contrato de prestação de serviços'. } \\
\text { Para as demais porcentagens, o valor obtido foi transformado para } \\
\text { uma escala de um a } 10 \text {. }\end{array}$ \\
\hline
\end{tabular}

por uma única pesquisadora aos coordenadores dos Sistemas da VQACH nos estados e municípios com assinatura prévia do termo de autorização livre e esclarecido. Foram enviados convites para participação na pesquisa a todas as Secretarias de Saúde (estaduais e municipais); conforme disponibilidade do participante, a entrevista foi realizada no local de trabalho ou nas reuniões técnicas sobre a VQACH, convocadas pelo nível central. O protocolo de pesquisa foi aprovado pelo Comitê de Ética em Pesquisa com Seres Humanos da Universidade Federal de Viçosa.

\section{Análise dos determinantes contextuais}

Foram analisados 16 critérios, compreendidos em três atributos (descentralização, aceitabilidade, coordenação) (Quadro 2) e treze indicadores de Saúde e Saneamento (Mortalidade geral; Mortalidade infantil); Cobertura do abastecimento público geral; Cobertura do abastecimento urbano; Porcentagem de investimento em Saúde; Porcentagem de investimento em Saneamento; Índice de Risco Relacionado com a Qualidade da Água (IRCA), socioeconômicos (Índice de Condições de Vida - ICV); Necessidades Bási- 
cas Insatisfeitas (NBI); Índice de Pobreza Multidimensional (IPM); Índice de Desenvolvimento (ID) e administrativos (Eficiência do Município); Índice de Desempenho Integral (IDI); Índice de Desempenho Fiscal (IDF). Informações sobre os indicadores foram obtidas no Departamento Administrativo Nacional de Estatísticas (DANE) e no Departamento de Planejamento Nacional (DPN), da Colômbia.

Para a análise foram considerados apenas os 26 estados e o distrito capital Bogotá. Os valores dos determinantes contextuais foram correlacionados com o grau de implementação mediante análise de regressão linear múltipla ajustada. Inicialmente, as séries de dados foram testadas para normalidade (Teste de Shapiro-Wilk) e hemocedasticidade (Teste de Breusch-Pagan) e, posteriormente, realizou-se análise de regressão univariada. Variáveis estatisticamente significantes $(5 \%)$ foram escolhidas para as análises multivariadas finais. As análises foram realizadas no Programa R e interpretadas considerando o nível de significância de 5\%.

\section{Resultados}

Dentre as unidades analisadas, 10,3\% dos territórios apresentaram ações de VQACH classificadas como 'implementado' (3 estados e a cidade de Bogotá); 64,1\% apresentaram nível 'parcialmente implementado' (19 estados e 6 municípios); 23,1\% 'incipiente' (3 estados e 6 municípios) e 2,6\% não apresentaram ações implementadas (um estado). A média geral do grau de implementação para os territórios analisados foi $57,9 \%$, sendo: $80,7 \%$ para os territórios classificados como 'implementados'; $63,7 \%$ para os 'parcialmente implementados'; $36,1 \%$ para os 'incipientes'; e 17,4\% para o estado não implementado. A distribuição dos graus de implementação segundo as categorias populacionais dos territórios evidencia a redução do grau de implementação das ações, à medida que diminui o porte populacional, sendo isso mais claro para os municípios (Figura 2).

Os escores finais de implementação dos atributos desagregados por estados e municípios (Figura 3) mostram valores mais baixos para a maioria dos atributos para os municípios, excetuando-se o atributo 'educação e participação comunitárias'. Para os atributos 'rede laboratorial', 'sistemas de informação', 'recursos humanos' e 'análises e investigação', as diferenças entre estados e municípios foram maiores $(>2,0)$; para

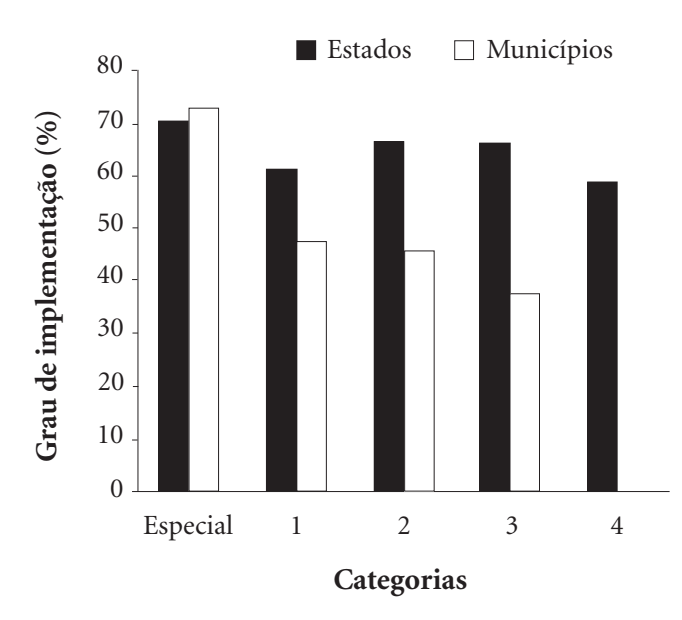

Figura 2. Grau de implementação do Sistema de VQACH, segundo categorias populacionais das unidade territoriais, Colômbia.

os atributos 'universalidade', 'intersetorialidade', 'recursos materiais e infraestrutura', 'monitoramento da qualidade da água', 'atuação junto aos responsáveis pelas fontes de distribuição de água' e 'disponibilização das informações', as diferenças foram menores $(<2,0)$.

No componente estrutura, a universalidade das ações esteve caracterizada pela atuação nos sistemas de abastecimentos convencionais (100\%), com menor atuação em fontes e poços comunitários $(51,3 \%)$, distribuição por veículo transportador $(38,5 \%)$, instalações em condomínios/prédios (30,7\%) e fontes individuais e/ ou intradomiciliares (17,9\%). Para os grupos populacionais especiais, a maior atuação foi nas zonas rurais $(53,8 \%)$, seguida de vilarejos $(33,3 \%)$ e comunidades étnicas $(35,9 \%)$. O baixo desempenho da VQACH nesses contextos foi frequentemente relacionado pelos entrevistados a problemas de acessibilidade, falta de segurança e falta de transporte. Destacam-se, ainda, baixos percentuais de atuação da VQACH em áreas próximas às cidades (periferias urbanas - 25,6\%; estratos de renda baixa - 23,1\% e assentamentos $-30,7 \%$ ), embora se caracterizem por maior facilidade de acesso.

Com relação à intersetorialidade, somente $12(30,7 \%)$ territórios afirmaram articular ações com outros setores, sendo as autoridades ambientais as mais mencionadas pelos participantes. De forma positiva, ressaltamos que os par- 


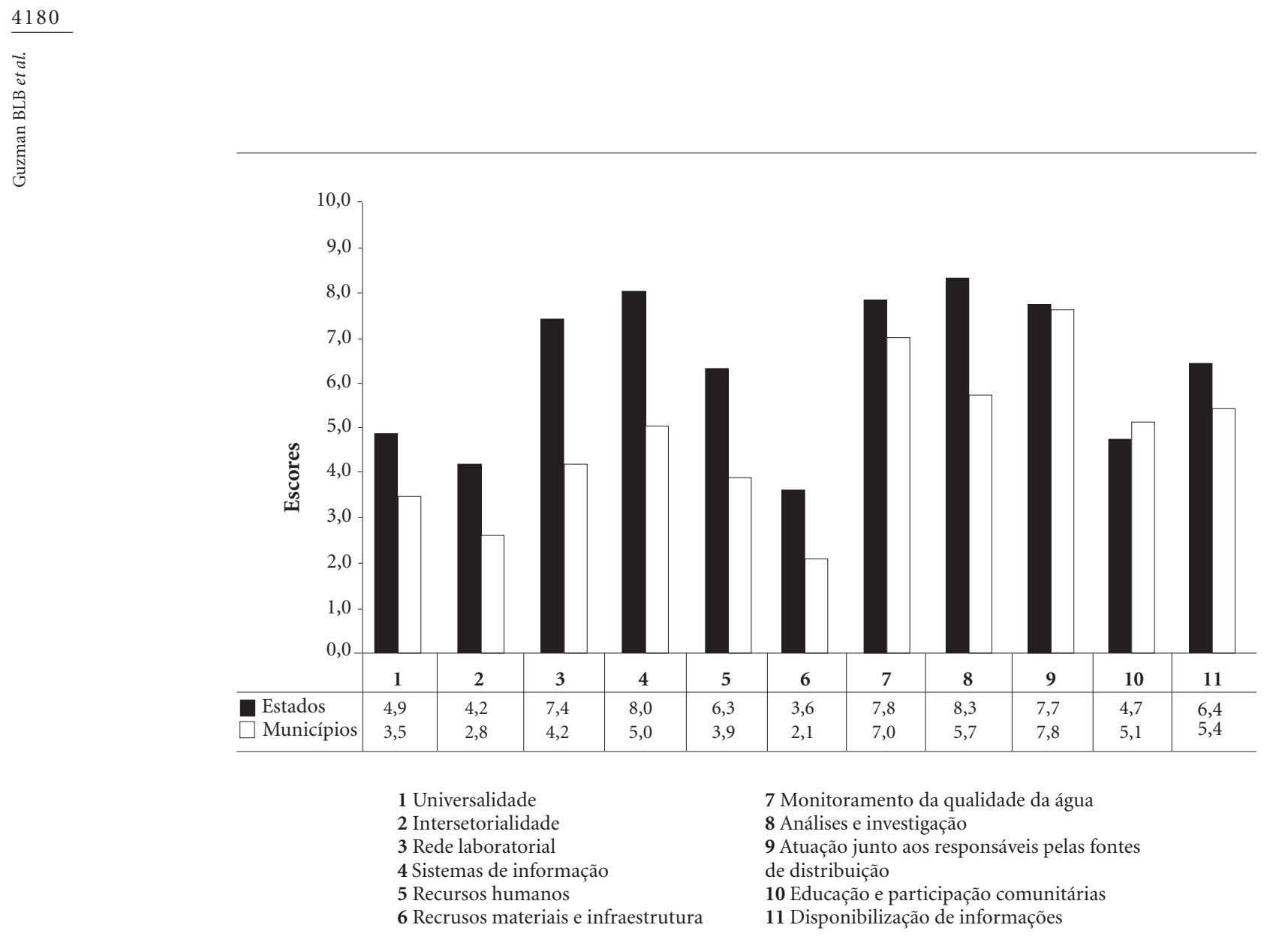

Figura 3. Escores finais para os atributos do Sistema de Vigilância da Qualidade da Água para Consumo Humano, Colômbia.

ticipantes apresentaram conhecimento sobre o conceito de intersetorialidade e da importância do mesmo para a VQACH.

Considerando os atributos 'rede laboratorial' e 'sistemas de informação', 69,2\% dos territórios conheciam o programa de laboratórios PICCAP e 79,5\%, a estrutura e o funcionamento do sistema de informação SIVICAP. Os participantes afirmaram que esses sistemas eram desenvolvidos e forneciam apoio para execução das ações da VQACH. Dentre as dificuldades mencionadas, citam-se, para o SIVICAP, a falta de suporte técnico e de recursos para o uso do aplicativo e, para o PICCAP, a falta de infraestrutura dos laboratórios (insumos e equipamentos) e de análises para pesquisa de agrotóxicos.

Para o atributo 'recursos humanos', as maiores dificuldades estiveram relacionadas à falta e/ ou intermitência na contratação de recursos humanos, rotatividade dos profissionais, acúmulo de atividades, vinculação não formal com a instituição e pouca experiência dos coordenadores em alguns territórios. De forma positiva, foi identificado que os coordenadores, em sua maioria, tinham formação superior completa.

$\mathrm{O}$ atributo 'recursos materiais e infraestrutura' recebeu os menores valores de escores, seja para estados ou municípios. Provavelmente, isso se deu pela recorrente citação nesse critério de aspectos relacionados a recursos humanos, embora houvesse item específico no instrumento de coleta de dados referente a esse aspecto. Ainda assim, foram assinaladas como fragilidades: clientelismo, falta de compromisso administrativo e político e falta de gestão e planejamento para a disponibilização de recursos.

No componente processo, os atributos 'monitoramento da qualidade da água', 'análise e investigação' e 'atuação junto aos responsáveis pelas fontes de distribuição de água’ mostraram altos valores de escores. Quanto ao 'monitoramento da qualidade da água', 69,2\% dos territórios elaboravam plano de amostragem próprio; $84,6 \%$ procuravam realizar coletas em pontos acordados com os responsáveis pelo abastecimento de água e $100 \%$ realizavam pesquisa de parâmetros físi- 
cos, químicos e microbiológicos. Apenas 43,6\% realizavam monitoramento de agrotóxicos. A ausência de recursos técnicos, humanos e financeiros foi a principal dificuldade para efetivação do monitoramento, principalmente quanto à cobertura e frequência.

Para o atributo 'análise e investigação', 94,9\% das autoridades elaboravam o IRCA, 74,3\% o mapa de risco e $61,5 \%$ o formulário único de inspeção, ainda que, para esse último, os participantes mencionassem dificuldades relacionadas a não adequação do formulário aos sistemas de abastecimento não convencionais e de pequeno porte. Outros procedimentos mencionados foram análise final da qualidade da água distribuída (84,6\%), elaboração de relatórios (97,0\%) e investigações de surtos relacionados com a água para consumo $(79,5 \%)$. Em menor proporção, observou-se que 56,4\% dos territórios investigavam os resultados não conformes sobre a qualidade da água; 66,7\% utilizavam as informações obtidas para planejamento e tomada de decisões e $69,2 \%$ realizavam análises integradas entre o banco de dados da VQACH e de outros sistemas de informação. Poucas informações fornecidas puderam explicar a ausência dessas ações. Entretanto, foi mencionada a falta de gestão mais ágil das informações, por exemplo, a interação do trabalho de campo com o laboratório, permitindo a identificação de situações de risco e a definição de estratégias de intervenção mais adequadas, impactando a capacidade de resolubilidade dos problemas detectados pelos territórios.

$\mathrm{Na}$ 'atuação junto aos responsáveis pelas fontes de distribuição de água', observou-se que $94,8 \%$ dos territórios realizavam visitas aos sistemas de abastecimento; $61,5 \%$ realizavam supervisão do autocontrole; $69,2 \%$ realizam ações em conjunto com os responsáveis pelo abastecimento e $61,5 \%$ promoviam diálogos entre as partes para solução dos problemas detectados.

Com relação à 'educação e participação comunitárias', poucas ações foram realizadas pelos territórios, sendo que $23,1 \%$ desenvolviam atividades de educação em Saúde envolvendo o tema qualidade da água e 17,9\% promoveram o uso/ conservação/manipulação adequado/a da água. Ainda, 46,1\% dos territórios afirmaram divulgar informação sobre as responsabilidades dos usuários na preservação da qualidade da água para consumo. A participação da comunidade no desenvolvimento de ações de VQACH foi pouco evidenciada: $20,5 \%$ dos territórios procuravam vincular a comunidade a atividades de vigilância, e 23,0\% afirmaram promover a criação de espa- ços e fóruns para discussão das ações e de temas relacionados à qualidade da água.

No atributo 'disponibilização de informações', 46,2\% dos territórios disponibilizavam informações sobre qualidade da água para a população; $51,3 \%$ para outros setores e 59\% disponibilizavam informações em situação de risco. Quanto aos canais/meios de disponibilização da informação para a população, foram mencionados: SIVICAP (38,8\%), solicitações, normalmente de indivíduos/pessoas, realizadas à autoridade de Saúde (51,20\%) e informes, cartazes ou meios de comunicação como rádio (5,12\%).

O modelo final ajustado entre os determinantes contextuais e o grau de implementação de VQACH incluiu as variáveis: IPM (Xi1 = -2,69; $\mathrm{p}=0,011)$, cobertura de aqueduto geral ( $\mathrm{Xi} 2=$ $3,11 ; \mathrm{p}=0,004)$, IRCA (Xi1 = 1,70; $\mathrm{p}=0,097)$, descentralização (Xi1 $=2,95 ; \mathrm{p}=0,006)$, aceitabilidade (Xi1 $=-3,06 ; \mathrm{p}=0,004)$, coordenação $(\mathrm{Xi1}=3,94 ; \mathrm{p}=0,0004)$.

\section{Discussão}

A metodologia utilizada permitiu conhecer as diferentes formas de atuação da VQACH nos territórios, mostrando que o Sistema se encontra parcialmente implementado, estando particularmente fortalecido em relação à produção e sistematização de dados. Por outro lado, foram identificadas desigualdades das práticas da VQA$\mathrm{CH}$ entre os territórios.

$\mathrm{Na}$ VQACH na Colômbia, prevalecem enfoques tradicionais de vigilância dos fatores ambientais, tratados de forma isolada da complexa cadeia de causalidade, constatado pelo desenvolvimento de ações de fiscalização dos sistemas de abastecimento em detrimento de ações de promoção da saúde, além da falta de aplicação das informações produzidas para a definição de estratégias de melhoria da qualidade da água e da saúde. Ressalta-se a percepção do exercício da VQACH como mera ação de fiscalização, externa ao sistema de abastecimento, sem um caráter mais independente ou pró-ativo de desenvolvimento de ações relacionadas à melhoria da qualidade da água e promoção da Saúde da população. Essa abordagem tem origem nas estratégias adotadas pelo setor saneamento e de recursos hídricos, que comumente tratam de forma independente e envolvem intervenções pontuais de caráter tecnológico para modificar o estado da qualidade da água.

No exercício da VQACH exige-se, primeiro, o entendimento de que saúde e ambiente estão 
fortemente relacionados e, segundo, que nessa complexa relação interagem fatores biológicos, econômicos, políticos e culturais, de forma a oportunizar a intervenção sobre os fatores determinantes dos agravos numa perspectiva ampla, consequente e eficaz ${ }^{17}$. Nesse sentido, são necessárias abordagens interdisciplinares e transdisciplinares, além do estímulo e exercício de processos participativos envolvendo diferentes setores da sociedade.

Na Colômbia, historicamente, têm-se observado dificuldades na conceituação e definição de normativas que conduzam à promoção da saúde, impedindo o reconhecimento da complexidade dos processos Saúde-doença e seus determinantes pelos diferentes atores (privados/públicos) que interagem e atuam na área da Saúde e suas interfaces ${ }^{18,19}$. O modelo de vigilância da Saúde Ambiental, voltado para a promoção da Saúde, pode ser considerado um eixo reestruturante da forma de atuar em Saúde, propiciando a criação de ambientes saudáveis, a busca da equidade em Saúde, da universalidade das ações e de alternativas que abordem de maneira integral os problemas de Saúde.

As limitações identificadas na universalidade das ações da VQACH podem levar à exclusão de grupos/população, aprofundando as desigualdades. Tais limitações podem estar relacionadas com as disposições da própria legislação colombiana, que determina que as ações de VQACH se apliquem às pessoas prestadoras, figuras de constituição legal que abastecem ou distribuem água para consumo humano, bruta ou tratada, excluindo outras formas e grupos populacionais que não se organizem enquanto 'pessoa prestadora'. Além disso, apesar da abrangência do texto legal, definindo que as ações se aplicam a todas as pessoas prestadoras, percebe-se que a abordagem das ações prioriza os sistemas de abastecimento de água, excluindo outras fontes.

Ainda que exista compreensão da necessidade de ações intersetoriais, o comprometimento e a integração de diferentes setores no desenvolvimento de ações não são de fato concretizados. A efetivação da intersetorialidade é tarefa complexa, devendo ser promovida mediante o respeito pelas diferentes visões e contribuições dos setores; a superação das hierarquias institucionais e das relações de poder existentes entre as corporações, profissionais, setores, políticas e segmentos sociais; a criação de canais e linguagem que envolva discussões sobre as visões, contribuições e possíveis soluções que permitam trabalhos coletivos e a promoção de espaços que envolvam a sociedade civil como parte essencial das soluções ${ }^{20}$. O nível nacional tem o importante papel de atuar como mediador, fornecendo elementos conceituais, técnicos e operativos que facilitem a efetivação da intersetorialidade.

Ações de educação/participação comunitárias e a disponibilização de informação são fundamentais na medida em que aumentam a consciência sanitária dos cidadãos e a proteção dos ambientes, ampliando as capacidades e o protagonismo das comunidades e incrementado seu poder técnico e político na definição de prioridades e estratégias para alcançar melhor nível de Saúde e na construção de mecanismos para a reivindicação de políticas públicas saudáveis ${ }^{17}$. A participação da comunidade é componente desejável para a $\mathrm{VQACH}$, tanto ao valorizar conhecimentos e experiência locais na identificação de problemas no abastecimento, quanto por envolver a comunidade em atividades participativas, como inspeção sanitária ou coletas de amostras em locais de difícil acesso para o serviço de Saúde.

No referente à disponibilização de informação, é importante estabelecer 'canais' adequados e eficientes para todos os serviços, setores e atores envolvidos com o abastecimento de água para consumo humano, permitindo realizar de forma apropriada a comunicação do risco e, consequentemente, desencadear estratégias eficazes de correção das deficiências existentes. Nesse sentido, é necessário avaliar os mecanismos mencionados pelos/as entrevistados/as para determinar em que medida as informações estão sendo disponibilizadas e causando impacto positivo na Saúde.

$\mathrm{Na}$ operacionalização das ações, evidenciaram-se limitações significativas nos aspectos recursos humanos, materiais e infraestrutura, coordenação e governança. Debilidades dos territórios para o desenvolvimento de programas de Saúde Pública na Colômbia têm sido assinaladas por diferentes estudos ${ }^{21-24}$. Essas fragilidades têm sido relacionadas aos efeitos tardios das reformas induzidas por diferentes legislações, que determinaram a descentralização dos territórios, outorgando competências e recursos aos municípios e estados em um contexto de fragilidade política e múltiplos interesses econômicos ${ }^{25,26}$.

Em relação aos recursos humanos, as fragilidades têm sido relacionadas à falta de regulação trabalhista devido ao surgimento de novos modelos de vinculação de trabalho, levando à flexibilização contratual, instabilidade e precarização do emprego e dos salários. Alguns autores afirmam que as habilidades administrativas requeridas para subcontratar e regular as contratações pa- 
recem ser afetadas pela falta de governança dos territórios ${ }^{27,28}$.

A governança nas novas democracias depende do desenho institucional e de sua adequação nas sociedades consolidando a relação EstadoSociedade ${ }^{29}$, processo que se tem dado de forma lenta na Colômbia, onde os arranjos institucionais são débeis e não têm permitido e fortalecido a autonomia da gestão dos territórios e a efetivação das práticas de Saúde. Para fortalecer as ações na área da Saúde, e consequentemente da VQACH, é necessário que o estado garanta o desenvolvimento da capacidade de gestão dos diferentes níveis e promova a participação e controle social, produzindo uma cultura política a favor da Saúde, propiciando abertura aos novos cenários de gestão em Saúde Ambiental nos territórios. Nesse estudo, a descentralização das ações apresentou correlação positiva e estatisticamente significante com o grau de implementação.

\section{Colaboradores}

BLB Guzman trabalhou na construção e planejamento da pesquisa; coleta, organização, análise e interpretação dos dados; elaboração, redação e revisão crítica do manuscrito; GN Tovar trabalhou na coleta dos dados e revisão crítica do manuscrito; PD Bevilacqua trabalhou na construção e planejamento da pesquisa; organização, análise e interpretação dos dados; elaboração, redação e revisão crítica do manuscrito.

\section{Agradecimentos}

À CAPES pela concessão da bolsa de estudos. Aos pesquisadores e profissionais das secretarias estaduais e municipais de saúde do Brasil e da Colômbia e ao Instituto Nacional de Saúde da Colômbia pela participação no estudo.
Tem sido apontado que falências na efetivação de programas de VQACH em países em desenvolvimento resultam muitas vezes da opção por metodologias adotadas em países desenvolvidos, apresentando, assim, deficiências significativas, derivadas não somente das diferenças socioeconômicas, mas também da natureza dos serviços de abastecimento de água ${ }^{30}$. Na América Latina, têm se observado fragilidades similares às encontradas no presente estudo, a exemplo do estudo realizado no Brasil, que demonstrou distanciamento entre a formulação do programa de VQACH e sua implementação na instância municipal $^{31}$. Portanto, são essenciais estratégias inovadoras e realistas que se adaptem aos contextos administrativos e institucionais dos países da região e que sejam acompanhadas do fortalecimento da governança.

\section{Referências}

1. Goodstadt M, Hyndman B, McQueen DV, Potvin L, Springett J, Ziglio E. Evaluation in health promotion: principles and perspectives. Geneva: WHO Regional Office Europe; 2004. (No. 92)

2. Salazar L, Vélez JA. Hacia la búsqueda de efectividad en promoción de la salud en América Latina. Cien Saude Colet 2004; 9(3):725-730.

3. Colombia. Ministerio de Planeación Social. Consejo Nacional de Política Económica Social. Lineamientos para la formulación de la política integral de salud ambiental con énfasis en los componentes de calidad de aire, calidad de agua y seguridad química. Bogotá: Ministerio de Planeación Social; 2008.

4. Colombia. Ministerio de Salud y Protección Social. Plan Decenal de Salud Pública 2012-2021: La salud en Colombia la construyes tú. Bogotá: Ministerio de Salud y Protección Social; 2013.

5. Pinto VG, Heller L, Bastos RKX. Drinking water standards in South American countries: convergences and divergences. J Water Health 2012; 10(2):295-310. 
6. Colombia. Decreto n ${ }^{\circ} 1575$ de 9 de mayo de 2007. Establece el Sistema para la Protección y Control de la Calidad del Agua para Consumo Humano. Diario Oficial 2007; 9 may.

7. Champagne F, Brousselle A, Hartz ZMA, Contandriopoulos AP. Modelizar as Intervenções. In: Brousselle A, Champagne F, Contandriopoulos AP, Hartz ZMA, organizadores. Avaliação conceitos e métodos. Rio de Janeiro: Fiocruz; 2011. p. 61-74.

8. Yin RK. Estudo de caso: planejamento e métodos. $3^{\mathrm{a}}$ ed. Porto Alegre: Bookman; 2005.

9. Bardin L. Análise de conteúdo. Lisboa: Edições 70; 1977.

10. Colombia. Ley n. ${ }^{\circ} 617$ de 6 octubre de 2000. Reforma parcialmente la Ley 136 de 1994, el Decreto Extraordinario 1222 de 1986, se adiciona la ley orgánica de presupuesto, el Decreto 1421 de 1993, se dictan otras normas tendientes a fortalecer la descentralización, y se dictan normas para la racionalización del gasto público nacional. Diario Oficial 2000; 9 oct.

11. Departamento de Planeación Nacional. Información Básica territorial [acessado 2013 jun 12]. Disponível em: https://www.dnp.gov.co/Programas/DesarrolloTer ritorial/Gesti\%C3\%B3nP\%C3\%BAblicaTerritorial/ Informaci $\% \mathrm{C} 3 \% \mathrm{~B} 3 \mathrm{nB} \% \mathrm{C} 3 \% \mathrm{~A} 1$ sicaTerritorial.aspx.

12. Hartz ZMDA. Avaliação dos programas e saúde: perspectivas teórico metodológicas e políticas institucionais. Cien Saude Colet 1999; 4(2):341-353.

13. Donabedian A. Una aproximación a la monitorización de la calidad asistencial (primera parte). Rev Calid Asist 1991; 6(1):1-6.

14. Denis JL, Champagne F. Análise da implantação. In: Hartz ZMA, organizador. Avaliação em saúde: dos modelos conceituais à prática na análise da implantação de programas. Rio de Janeiro: Editora Fiocruz; 1997. p. 49-88.

15. Colombia. Ministerio de la Protección Social. Ministerio de Ambiente, Vivienda y Desarrollo Territorial. Resolución n ${ }^{\circ} 2115$ de 22 junio de 2007. Por medio de la cual se señalan características, instrumentos básicos y frecuencias del sistema de control y vigilancia para la calidad del agua para consumo humano. Diario Oficial 2007; 22 jun.

16. Souza LEPF, Silva LMV, Hartz ZMA. Conferência de consenso sobre a imagem-objeto da descentralização da atenção à saúde no Brasil. In: Hartz ZMA, Silvia LMV, organizadores. Avaliação em saúde: dos modelos teóricos à prática na avaliação de programas e sistemas de saúde. Rio de Janeiro: Editora EDUFBA, Fiocruz; 2005. p. 65-103.

17. Buss PM. Promoção da saúde e qualidade de vida. Cien Saude Colet 2000; 5(1):163-177.

18. Eslava-Castañeda JC. Repensando la promoción de la salud en el sistema general de seguridad social en salud. Rev Salud Pública 2006; 8(2):106-115.

19. Mantilla BP. Evolución conceptual y normativa de la promoción de la salud en Colombia. Rev Univ Ind Santander Salud 2011; 43(3):299-306.
20. Silva KL. Rodrigues AT. Ações intersetoriais para promoção da saúde na Estratégia Saúde da Família: experiências, desafios e possibilidades. Rev Bras Enferm 2010; 63(5):762-769.

21. Cerna CA, Kroeger A. La reforma del sector salud en Colombia y sus efectos en los programas de control de tuberculosis e inmunización. Cad Saude Publica 2002; 18(6):1771-1781.

22. Molina G, Montoya N, Rodriguez CM, Spurgeon, P. Descentralización del sector salud en Colombia: análisis de 91 municipios. Rev Fac Nac Salud Pública 2006; 24(1):48-60.

23. López YL, González C, Gallego BN, Moreno AL. Rectoría de la vigilancia en salud pública en el sistema de seguridad social en salud de Colombia: estudio de casos. Biomédica 2009; 29(4):567-581.

24. Chavez BM, Velasquez LE. Análisis de la gestión territorial: Encuesta Nacional de Salud 2007, Colombia 2011. Rev. Fac. Nac. Salud Pública 2012; 30(1):57-65.

25. Molina GM. Rol de los partidos políticos en la provisión de servicios de salud, Colombia 2007-2008. Rev Fac Nac Salud Pública 2009; 27(1):66-67.

26. Lujan FJY. Luces y sombras de la reforma de la salud en Colombia. Ley 100 de 1993. Rev Gerenc Polit Salud 2010; 9(19):118-123.

27. Florez Acosta JH, Atehortua Becerra SC, Arenas Mejia AC. Las condiciones laborales de los profesionales de la salud a partir de la Ley 100 de 1993: evolución y un estudio de caso para Medellín. Rev Gerenc Polit Salud 2009; 8(16):107-131.

28. Groote T, Paepe P, Unger J. Las consecuencias del neoliberalismo Colombia: prueba in vivo de la privatización del sector salud en países en desarrollo. Rev Fac Nac Salud Pública 2007; 25(1):106-117.

29. Azevedo S, Anastasia F. Governança, "accountability"e responsividade. Rev Econ Polt 2002; 22(1):79-97.

30. Howard G, Bartram J. Effective water supply surveillance of developing countries. J Water Health 2005; 3(1):31-43.

31. Queiroz ACL, Cardoso LSM, Silva, SCF, Heller L, Cairncross S. Programa Nacional de Vigilância em Saúde Ambiental Relacionada à Qualidade da Água para Consumo Humano (Vigiagua): lacunas entre a formulação do programa e sua implantação na instância municipal. Saúde Soc 2012; 21(2):465-478.

Artigo apresentado em 07/06/2014

Aprovado em 11/07/2014

Versão final apresentada em 12/07/2014 